\title{
Radiologically Inserted Gastrostomy (RIG) at a Tertiary Center: Periprocedural Safety including Rationalization of Antibiotic Prophylaxis
}

\author{
Warren Clements ${ }^{1,2,3, \odot} \quad$ Yasmin Shvarts $^{1} \quad$ Jim Koukounaras ${ }^{1,2, \odot} \quad$ Tuan D. Phan ${ }^{1, \odot ~ G e r a r d ~ S . ~ G o h ~}{ }^{1,2, \odot}$ \\ Tim Joseph ${ }^{1, \odot}$ Ronny Kuang ${ }^{1, \odot}$ Lisa Murnane ${ }^{4, \odot}$
}

\footnotetext{
${ }^{1}$ Department of Radiology, Alfred Hospital, Melbourne, Victoria, Australia

${ }^{2}$ Department of Surgery, Monash University, Melbourne, Victoria, Australia

${ }^{3}$ National Trauma Research Institute, Melbourne, Victoria, Australia

${ }^{4}$ Department of Nutrition and Dietetics, Alfred Hospital, Melbourne, Victoria, Australia
}

J Clin Interv Radiol ISVIR:2021;5:11-15

\begin{abstract}
Address for correspondence Warren Clements, BBiomedSc (Hons), MBBS, FRANZCR, EBIR, Department of Radiology, Alfred Health, 55 Commercial Road, Melbourne, Victoria 3004, Australia (e-mail: w.clements@alfred.org.au).
\end{abstract}

\section{Abstract}

Keywords

- gastrostomy

- RIG

- antibiotics
Introduction Long-term percutaneous enteral nutrition forms an important part of treatment for patients with an inability to meet nutrient requirements orally. Radiologically inserted gastrostomy (RIG) is an alternative to the traditionally performed percutaneous endoscopic gastrostomy technique. However, there is marked heterogeneity in the way that RIG is performed. In addition, the role for antibiotic prophylaxis during RIG insertion is not clearly established. This study aimed to assess the safety of RIG insertion using our technique including the role of antibiotics in RIG insertion.

Method Retrospective study over 5 years at a tertiary teaching hospital. Periprocedural or early complications within the first 2 weeks of the procedure were collected and correlated with the use of prophylactic antibiotics.

Results A total of 116 patients met the inclusion criteria. 18-French tube was used in $96.6 \%$. Note that $58.6 \%$ of procedures were done with intravenous sedation. Prophylactic $1 \mathrm{~g}$ cefazolin was used in 70 patients with 1 case of infection. Procedures were performed without antibiotics in 46 patients with 3 infections, $p=0.20$.

There were two major complications (1.7\%) consisting of right gastric artery injury requiring embolization and gastric wall injury requiring laparotomy. There were 12 minor complications (10.3\%) including 4 cases of infection, 3 of severe pain, 1 of minor bleeding, 2 of early dislodgement, and 2 of leak/bypass of gastric contents around the tube.

Conclusion The technique used for RIG insertion at our institution results in a low complication rate. In addition, this study shows no significant difference in early peristomal infection rate with the use of antibiotic prophylaxis.
DOI https://doi.org/

$10.1055 / \mathrm{s}-0041-1723098$ ISSN 2457-0214.

\footnotetext{
(C) 2021. Indian Society of Vascular and Interventional Radiology. This is an open access article published by Thieme under the terms of the Creative Commons Attribution-NonDerivative-NonCommercial-License, permitting copying and reproduction so long as the original work is given appropriate credit. Contents may not be used for commercial purposes, or adapted, remixed, transformed or built upon. (https://creativecommons.org/licenses/by-nc-nd/4.0/).

Thieme Medical and Scientific Publishers Pvt. Ltd. A-12, 2nd Floor, Sector 2, Noida-201301 UP, India
} 


\section{Introduction}

Long-term percutaneous enteral nutrition forms an important part of treatment for patients who are malnourished or at nutrition risk with an inability to meet nutrient requirements orally. ${ }^{1}$

The placement of a gastrostomy tube is performed in one of three ways. Percutaneous endoscopic gastrostomy (PEG) is a simple and effective method which is commonly used. The main alternative to PEG is radiologically inserted gastrostomy (RIG) in which fluoroscopic guidance is used to puncture the gastric body before placing the tube. ${ }^{2}$ Surgical gastrostomy is less commonly used due to high complication rates.,4

A recent study of procedures at an Australian center showed that more PEGs were placed than RIGs during the 2-year period of their study. ${ }^{5}$ This has been supported by similar overseas data. ${ }^{6,7}$ Studies have shown a similar overall rate of procedural complications between PEG and RIG placement including a recently published prospective randomized controlled trial (RCT) of 214 children where the authors show no significant difference in the complication rate comparing the procedure type. ${ }^{2,8,9}$

It should be noted that there is a great deal of heterogeneity in the way that RIG is performed between practitioners and between institutions. The use of gastropexy or not, the number of gastropexy sutures, the size of tube, the tube type (e.g., pigtail or balloon), the use of prophylactic antibiotics, and the necessity of anesthetic involvement will all yield different responses between practitioners.

Antibiotic use in interventional radiology (IR) is also a controversial topic and many guidelines are based upon expert consensus rather than evidence. ${ }^{10}$ A recent prospective study randomized 70 patients to placebo or antibiotics and showed that there was a trend toward reduction in rate of peristomal infection after percutaneous gastrostomy when prophylactic antibiotics are administered; however, found no significant difference using an intention-to-treat analysis. ${ }^{11}$ This study used a 3-point gastropexy and 16-Fr pigtail tube technique. It was noted that a range of 20 different antibiotic regimens were used in that study. At our institution, the insertion protocol employed recommends the use of $1 \mathrm{~g}$ intravenous cefazolin to be given as a single dose at the beginning of the procedure; however, it is at the discretion of the IR given the lack of evidence to support decision making.

The purpose of our study was to retrospectively assess the safety and efficacy of RIG placement in a tertiary teaching IR unit using an 18-Fr balloon-type tube, and to assess the association of intravenous antibiotic prophylaxis with early postprocedure infection.

\section{Methods}

Approval for the conduct of this retrospective audit including a waiver of the need for individual patient consent was obtained by the Alfred Hospital Human Research and Ethics Committee, number 420/19.

The study covered all consecutive procedures performed over a 5-year period between January 1, 2014 and
January 1,2019 . Patients were identified using the radiology information system and picture and communications archive. All patients who received a primary gastrostomy (-Fig. 1) or primary transgastric jejunostomy insertion between the ages of 16 and 99 years were included. Patients were excluded if the procedure was a change of tube and not a primary tube insertion.

The hospital electronic medical record was then used to identify periprocedural or early postprocedural complications within the first 2 weeks of the procedure. Data collected included the indication for RIG, age, gender, use of anesthetics, type of anesthetic, use of antibiotic prophylaxis, type of operator, size of balloon, volume to balloon, number of gastropexy sutures, and type of complication. The indication for RIG was considered to be the primary underlying medical condition resulting in the need for the procedure and classified into head and neck cancer, neurological insult/injury (e.g., stroke or traumatic brain injury), dysphagia, chronic disease (e.g., cystic fibrosis $[\mathrm{CF}]$ ), and gastroparesis. While many patients will require the tube due to malnutrition secondary to other disease, the underlying disease was considered the reason for the tube (e.g., reduced oral intake due to stroke resulting in malnutrition).

Technical success was defined as placement of a functioning gastrostomy at the conclusion of the procedure. Complications were categorized as bleeding requiring subsequent intervention, early tract infection, early tube dislodgement ( $<2$ weeks after the procedure), leak or bypass of the tube, severe pain lasting $>2$ days and needing intravenous analgesia, and injury to stomach, bowel, or liver. Infection was defined as early infection within 2 weeks of the procedure,

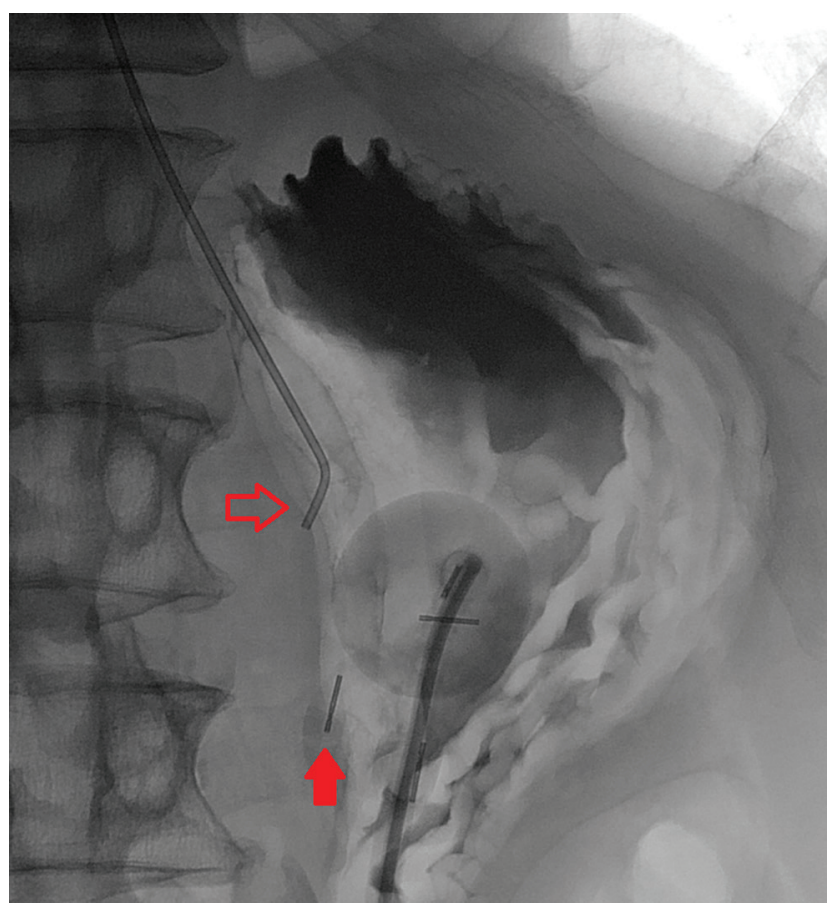

Fig. 1 Fluoroscopic image shows insertion of gastrostomy tube with 3-point gastropexy sutures (arrow) and the use of an angiographic catheter for gastric insufflation (open arrow). 
diagnosed clinically as peristomal infection, and requiring antibiotics for treatment.

Data was pooled and analyzed using Microsoft Excel (Microsoft Corp.) with Real Statistics add-on. Where relevant to the type of data, data was represented as number (percentage), median (range), or mean (standard deviation). A two-tailed $p$-value of less than 0.05 was considered statistically significant.

\section{Results}

During the 5-year period of the study, 116 patients met inclusion criteria, including 111 gastrostomy and 5 transgastric jejunostomy procedures ( - Table $\mathbf{1}$ ). The mean age of patients was $61.1 \pm 17.2$ years and $69.0 \%$ were male.

The reason for insertion was head and neck cancer in 54 patients (46.6\%), neurological insult/injury in 38 (32.8\%), dysphagia in 12 (10.3\%), chronic disease in 9 (7.8\%), and gastroparesis in $3(2.6 \%)$ (-Table 2 ). Of the 9 patients with chronic disease there were 7 patients with $\mathrm{CF}, 1$ patient with non-CF-related bronchiectasis, and 1 patient with severe graft versus host disease following a bone marrow transplant.

Procedures were primarily performed by a radiology registrar or IR advanced training fellow in $80(69.0 \%)$ while a consultant interventional radiologist performed the procedure in $36(31.0 \%)$.

Technical success with a functional gastrostomy was achieved in $100 \%$ of patients. An 18-Fr tube (18-Fr gastrostomy feeding tube with Y-port, Covidien) was used in 112 patients (96.6\%) and 3-point gastropexy suture technique (Gastrointestinal Anchor Set, Halyard Healthcare) in

Table 1 Patient demographics

\begin{tabular}{|l|l|}
\hline Number of procedures & 116 \\
\hline Age (mean, SD) & $61.1 \pm 17.2$ \\
\hline Male gender (number, \%) & $80(69)$ \\
\hline Tube size (French) (median, range) & 18 \\
\hline Total number of complications (number, \%) & $14(12)$ \\
\hline Major complications (number, \%) & $2(1.7)$ \\
\hline Minor complications (number, \%) & $12(10)$ \\
\hline Use of prophylactic antibiotics (number, \%) & $70(60)$ \\
\hline Procedures performed by trainee (number, \%) & $80(69)$ \\
\hline
\end{tabular}

${ }^{\mathrm{a}} \mathrm{g}$ cefazolin intravenously preprocedure.

Table 2 Indications for procedure and rates of complication

\begin{tabular}{|l|l|l|}
\hline Indication & $\begin{array}{l}\text { Number } \\
(\%)\end{array}$ & $\begin{array}{l}\text { Complications } \\
(\%)\end{array}$ \\
\hline Gastroparesis & $3(2.6)$ & $1(33.3)$ \\
\hline Chronic disease $^{\mathrm{a}}$ & $9(7.8)$ & $2(22.2)$ \\
\hline Head/neck cancer & $54(46.6)$ & $8(14.8)$ \\
\hline Dysphagia & $12(10.3)$ & $2(16.7)$ \\
\hline $\begin{array}{l}\text { Neurological condition/ } \\
\text { injury }\end{array}$ & $38(32.8)$ & $1(2.6)$ \\
\hline
\end{tabular}

aBronchiectasis in 8 out of 9 patients.
107 patients (92.2\%). The tube has a maximum balloon volume of $20 \mathrm{~mL}$ and the median volume of water administered was $15 \mathrm{~mL}$ (range $7-20 \mathrm{~mL}$ ).

All procedures were performed with the use of injected lidocaine to the skin and tract (10-15 mL 1\% lidocaine with adrenaline). Additionally, 68 procedures (58.6\%) were performed with intravenous sedation and 44 (37.9\%) under general anesthetic. A total of 4 were performed with only lidocaine and no intravenous sedative agent. Intravenous sedation was provided by IR (without anesthetic involvement) in 16 patients with the remaining performed by an anesthetist.

Prophylactic $1 \mathrm{~g}$ cefazolin was used in 70 patients (60.3\%) while no antibiotics were used in 46 (39.7\%) (-Table 3 ).

Complications were documented in 14 patients (12.1\%) (-Table 4). There were two major complications (1.7\%). The first was injury to a branch of the right gastric artery which required embolization for hemostasis ( $\boldsymbol{-}$ Figs. 2 A and $\mathbf{B}$ ). The second was a 41-year-old male with underlying CF and severe malnutrition with a body mass index of 17.4. The procedure was complicated by gastric wall injury associated with the gastrostomy entry site and required operative laparotomy and partial gastrectomy on the day of the procedure. However, the patient was still able to receive enteral nutrition.

There were 12 minor complications (10.3\%) including 4 cases of infection, 3 of severe pain, 1 of minor bleeding, 2 of early dislodgement, and 2 of leak/bypass of gastric contents around the tube. Of the patients with infection, 3 patients did not receive antibiotic prophylaxis (6.5\%) while 1 patient did receive antibiotic prophylaxis (1.4\%), $p=0.20$. Both patients with severe pain settled within 2 weeks of de-escalation with the use of in-hospital acute pain services. The patient with minor bleeding required 1-unit intravenous packed red blood cell transfusion but no further intervention. The first dislodgement occurred at day 6 and was an 18-Fr tube with $15 \mathrm{~mL}$ in the balloon, the second occurred at day 2 and was an 18-Fr tube with $20 \mathrm{~mL}$ in the balloon, both able to be replaced successfully. The two patients with bypass around the tube were successfully treated with drain tube upsize to $24-\mathrm{Fr}$.

Complications occurred in 10 procedures performed by a trainee (8.6\%) and in 4 performed by a consultant (3.4\%), $p=$ 0.83. In addition, of the 4 patients with early infection, 1 of 4 were procedures performed by a consultant while 3 out of 4 were performed by an advanced trainee. In terms of sedation, complications occurred in 9 out of 68 patients (13.2\%) who had sedation, 4 out of 44 (9.1\%) who had general anesthesia, and 1 out of 4 (25\%) patients with local anesthetic only, $p=0.58$. There were 8 complications in patients with head/ neck cancer, 2 with chronic disease, 2 with dysphagia, 1 with gastroparesis, and 1 with neurological insult/injury, $p=0.23$.

Table 3 Use of antibiotic prophylaxis

\begin{tabular}{|l|l|l|}
\hline Prophylactic antibiotics used $^{a}$ & Number (\%) & p-Value \\
\hline Yes & $70(60.3)$ & 0.20 \\
\cline { 1 - 2 } No & $46(39.7)$ & \\
\hline
\end{tabular}

a1 g cefazolin intravenously preprocedure. 
Table 4 Individual RIG complications

\begin{tabular}{|c|c|c|c|c|c|c|c|c|c|}
\hline Patient & Gender & $\begin{array}{l}\text { Age (in } \\
\text { years) }\end{array}$ & Indication & $\begin{array}{l}\text { Sedative } \\
\text { used }\end{array}$ & $\begin{array}{l}\text { Number of } \\
\text { gastropexy } \\
\text { sutures }\end{array}$ & $\begin{array}{l}\text { Volume } \\
\text { to } \\
\text { balloon } \\
\text { (mL) }\end{array}$ & $\begin{array}{l}\text { RIG size } \\
\text { (French) }\end{array}$ & Type of RIG & Complication \\
\hline 1 & Male & 71 & $\begin{array}{l}\text { Head/neck } \\
\text { cancer }\end{array}$ & Sedation & 3 & 15 & 18 & Gastrostomy & Leak \\
\hline 2 & Male & 68 & $\begin{array}{l}\text { Head/neck } \\
\text { cancer }\end{array}$ & Sedation & 3 & 15 & 18 & Gastrostomy & Bleeding major \\
\hline 3 & Male & 41 & Chronic disease & Sedation & 3 & 20 & 18 & Gastrostomy & Gastric injury \\
\hline 4 & Male & 64 & $\begin{array}{l}\text { Head/neck } \\
\text { cancer }\end{array}$ & GA & 3 & 18 & 18 & Gastrostomy & Pain \\
\hline 5 & Female & 51 & Gastroparesis & GA & 3 & 10 & 18 & Gastrostomy & Pain \\
\hline 6 & Female & 86 & $\begin{array}{l}\text { Head/neck } \\
\text { cancer }\end{array}$ & Sedation & 3 & 15 & 18 & $\begin{array}{l}\text { Transgastric } \\
\text { jejunostomy }\end{array}$ & Infection \\
\hline 7 & Female & 74 & $\begin{array}{l}\text { Head/neck } \\
\text { cancer }\end{array}$ & Sedation & 3 & 15 & 18 & Gastrostomy & $\begin{array}{l}\text { Early tube } \\
\text { dislodgement }\end{array}$ \\
\hline 8 & Male & 86 & Dysphagia & Sedation & 3 & 20 & 18 & Gastrostomy & $\begin{array}{l}\text { Early tube } \\
\text { dislodgement }\end{array}$ \\
\hline 9 & Male & 62 & $\begin{array}{l}\text { Head/neck } \\
\text { cancer }\end{array}$ & Sedation & 3 & 17 & 18 & Gastrostomy & Leak \\
\hline 10 & Female & 66 & $\begin{array}{l}\text { Head/neck } \\
\text { cancer }\end{array}$ & $\begin{array}{l}\text { Local anes- } \\
\text { thetic only }\end{array}$ & 3 & 15 & 18 & Gastrostomy & Infection \\
\hline 11 & Female & 70 & Dysphagia & GA & 3 & 7 & 18 & Gastrostomy & Bleeding minor \\
\hline 12 & Male & 69 & $\begin{array}{l}\text { Head/neck } \\
\text { cancer }\end{array}$ & Sedation & 3 & 20 & 18 & Gastrostomy & Infection \\
\hline 13 & Male & 58 & $\begin{array}{l}\text { Neurological } \\
\text { condition }\end{array}$ & GA & 3 & 20 & 18 & Gastrostomy & Infection \\
\hline 14 & Female & 26 & Chronic disease & Sedation & 3 & 15 & 18 & Gastrostomy & Pain \\
\hline
\end{tabular}

Abbreviations: GA, general anesthesia; RIG, radiologically inserted gastrostomy.
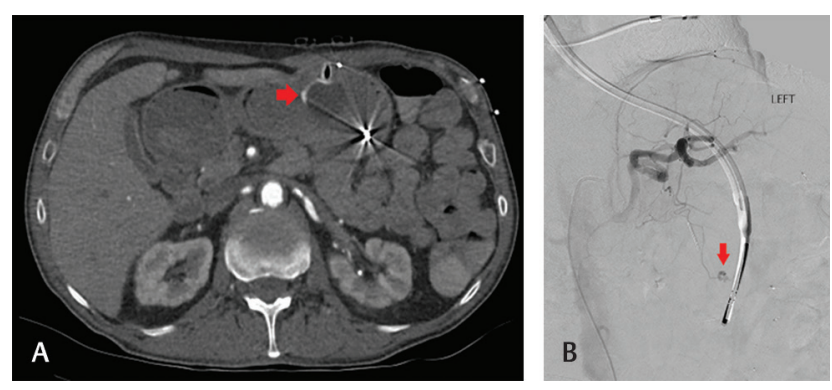

Fig. 2 (A) Axial arterial phase computed tomography (CT) shows extravasation of contrast next to the gastrostomy tube (arrow). (B) Angiography in a lateral plane shows active bleed via a branch off the right gastric artery, which was subsequently treated with embolization.

\section{Discussion}

RIG is a procedure commonly performed for long-term enteral nutrition and has been shown to have a similar safety profile to PEG. ${ }^{2-9}$ However, there is a great deal of heterogeneity in the way it is performed and the reporting of complications in literature.

This study over 5 years at a tertiary center shows that the use of predominantly 18 -Fr tubes, with $15 \mathrm{~mL}$ water into the balloon, and use of a 3-point gastropexy technique, results in a high level of technical success and a low level of complication.

A systematic review published by Yuan et al in 2020 covered 7 studies and 603 patients. The authors suggested major complication rates from RIG insertion of between 0 and $4 \%$ (pooled rate of $0.7 \%$ ), while minor complication rates between 0 and $31.8 \%$ (pooled rate 13.43\%). ${ }^{7}$ These rates are comparable to our study. In addition, technical success with a clinically functioning gastrostomy tube was achieved in all patients confirming this as an efficacious procedure.

The use of prophylactic antibiotics for insertion of gastrostomy tubes is a question that remains unanswered with very limited and low-quality data to interrogate routine use. ${ }^{10,11} \mathrm{~A}$ 2018 prospective RCT showed no significant difference in the rate of infection from use of antibiotics compared with placebo in their intention-to-treat analysis. ${ }^{11}$ Our study confirms these findings although it is acknowledged that the overall infection rate of $3.4 \%$ in our cohort is low and as such the study may be underpowered in this regard. The authors encourage more data on this area of IR in the setting of both RIG and other minimally invasive procedures, to allow more robust data to drive future societal guidelines on the role of prophylaxis. ${ }^{10}$

It was encouraging to see that in our cohort the type of inserter (IR or trainee under the supervision of an IR) had 
no association with the incidence of complications ( $p=0.83$ ). In addition, the use of general anesthetic or sedation also showed no significant association with the complication rate $(p=0.58)$. We acknowledge the high number of patients where the procedure was performed with anesthetic-assisted sedation as opposed to IR-led sedation. The majority of our patients with chronic disease as the primary reason for insertion was patients with $\mathrm{CF}$ ( \pm prior lung transplant) and they were deemed too high-risk for IR-led sedation. In addition, patients with head/neck cancer often had tumor above the larynx and so sedation without anesthetic was considered to be high airway risk. These factors coupled with fortunate availability of an anesthetist specifically for radiology 4 days a week heavily skewed the data toward the use of anesthetic support.

The overall volume of sterile water used to inflate the balloon varied from 7 to $20 \mathrm{~mL}$ (median $15 \mathrm{~mL}$ ), in a tube with a maximum volume permissible of $20 \mathrm{~mL}$. This variation reflects individual practice and the lack of evidence toward the actual volume needed to prevent dislodgement. The rate of early tube dislodgement in the first 14 days $(n=2)$ was only $1.7 \%$ and occurred in balloons with 15 - and $20-\mathrm{mL}$ volume, respectively. Data beyond 14 days was not collected as the study aimed to assess early technical success rather than long-term clinical success.

The authors acknowledge that a single-center retrospective audit will be underpowered to show changes in complication rates between measured parameters particularly for such low complication rates. However, this is also an inherent limitation of a procedure which is not performed with high frequency in any center. This study assessed purely technical and early periprocedural success and we acknowledge that long-term parameters such as tube dysfunction were not assessed which limits the impact of the findings. In addition, as a retrospective audit the results are prone to an inherent selection bias of the cohort. In considering this, however, patients referred for RIG insertion are often not suitable for PEG insertion and/or possess a difficult airway (due to head and neck cancer) which necessitated the use of anesthetics for safety. In addition, as a statewide referral center for CF, many of the patients in the chronic disease category have significant underlying lung disease and/or were recipients of lung transplantation which increased anesthetic risk.

In conclusion, this study showed a low overall complication rate from RIG insertion which is comparable with prior literature, even for a cohort of patients which require a heavy burden on anesthetic involvement for safety, and in a teaching hospital. In addition, the study showed no significant difference in the rate of infection with the use of antibiotic prophylaxis compared with RIG procedures performed without. The role of antibiotic prophylaxis for RIG and other IR procedures should be further explored so as to provide a higher level of evidence around which major societies and governing bodies can base recommendations.

\section{Conflict of Interest}

None declared.

\section{Acknowledgments}

None.

\section{References}

1 Bischoff SC, Austin P, Boeykens K, et al. ESPEN guideline on home enteral nutrition. Clin Nutr 2020;39(1):5-22

2 Bravo JG, Ide E, Kondo A, et al. Percutaneous endoscopic versus surgical gastrostomy in patients with benign and malignant diseases: a systematic review and meta-analysis. Clinics (São Paulo) 2016;71(3):169-178

3 Ljungdahl M, Sundbom M. Complication rate lower after percutaneous endoscopic gastrostomy than after surgical gastrostomy: a prospective, randomized trial. Surg Endosc 2006; 20(8):1248-1251

4 Rustom IK, Jebreel A, Tayyab M, England RJ, Stafford ND. Percutaneous endoscopic, radiological and surgical gastrostomy tubes: a comparison study in head and neck cancer patients. J Laryngol Otol 2006;120(6):463-466

5 Vidhya C, Phoebe D, Dhina C, Jayne S, Robert F. Percutaneous endoscopic gastrostomy (PEG) versus radiologically inserted gastrostomy (RIG): a comparison of outcomes at an Australian teaching hospital. Clin Nutr ESPEN 2018;23:136-140

6 Pannick S, Hicks L, Kim J, et al. Radiologically vs endoscopicallyplaced gastrostomy feeding tubes: an audit of current practice and clinical outcomes in a large, multi-site UK NHS trust. Endoscopy 2019;51(04):S85

7 Yuan TW, He Y, Wang SB, Kong P, Cao J. Technical success rate and safety of radiologically inserted gastrostomy versus percutaneous endoscopic gastrostomy in motor neuron disease patients undergoing: a systematic review and meta-analysis. J Neurol Sci 2020;410(March) :116622

8 Singh RR, Nah SA, Roebuck DJ, Eaton S, Pierro A, Curry JI; PEG-RIG trial collaborators. Double-blind randomized clinical trial of percutaneous endoscopic gastrostomy versus radiologically inserted gastrostomy in children. Br J Surg 2017; 104(12):1620-1627

9 Yuan Y, Zhao Y, Xie T, Hu Y. Percutaneous endoscopic gastrostomy versus percutaneous radiological gastrostomy for swallowing disturbances. Cochrane Database Syst Rev 2016; 2:CD009198

10 Venkatesan AM, Kundu S, Sacks D, et al. Practice guideline for adult antibiotic prophylaxis during vascular and interventional radiology procedures. J Vasc Interv Radiol 2010; 21(11):1611-1630

11 Ingraham CR, Johnson GE, Albrecht EL, et al. Value of antibiotic prophylaxis for percutaneous gastrostomy: a double-blind randomized trial. J Vasc Interv Radiol 2018;29(1):55-61.e2 